\title{
OPTIONS FOR BETTER QUALITY AND MORE ACCESSIBLE LONG-TERM CARE SERVICES \\ FOR THE ELDERLY IN POLAND (P169527)
}

\author{
Policy Note ${ }^{1}$
}

\begin{abstract}
${ }^{1}$ This note is prepared by Florentin Kerschbaumer (Jr Professional Officer, GSP03, World Bank), Wojciech Tomasz Sacha (Consultant, GSP03, World Bank), Audrey Sokolo (Élève directeur d'hôpital, EHESP - French School of Public Health), and Pirathees Sivarajah (Élève directeur d'hôpital, EHESP - French School of Public Health), under the guidance of Elena Glinskaya (Lead Economist, GSP02, Word Bank).
\end{abstract}


Contents

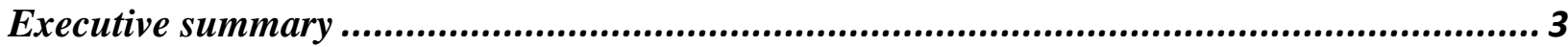

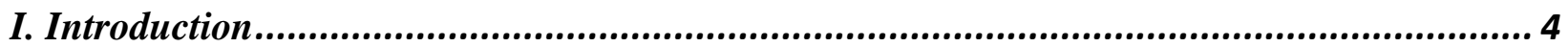

II. Supply of social care ............................................................................. 4

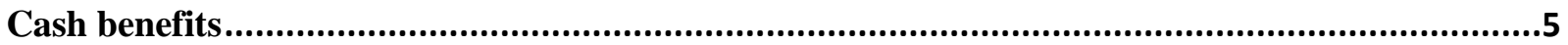

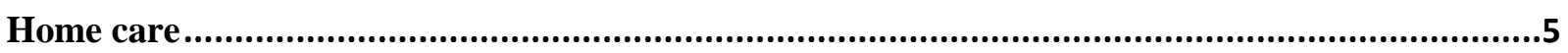

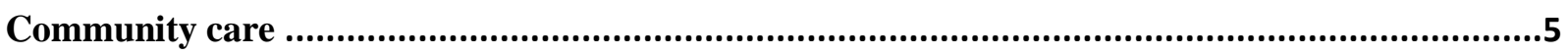

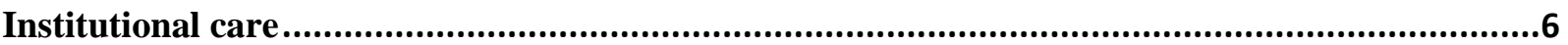

III. Coordination of care across health and social ministries, and across local and central authorities...................................................................................................................... 7

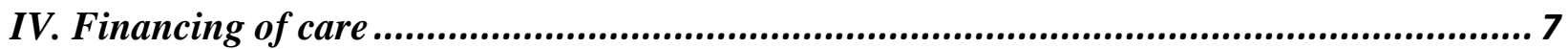

V. Private Sector engagement in care provision .....................................................8

VI. Human resources for medical and social care ......................................................... 9

VII. Technology ............................................................................................... 9

VII. Recent government initiatives ..................................................................... 10

VIII. Policy options ......................................................................................... 10

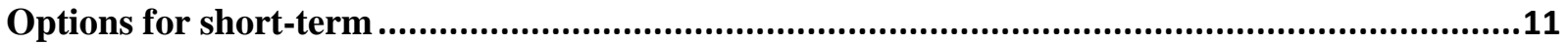

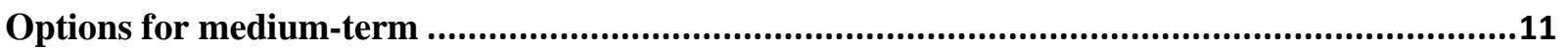

ANNEX

Annex 1: Organization of long-term care services in Poland ................................................13

Annex 2: Financing of LTC in Poland and other EU countires ............................................15

Annex 3: Some international comparisons of LTC systems.......................................................18 


\section{Executive summary}

The LTC agenda is receiving much attention in Poland's public debate. Rapid population ageing, a result of increasing longevity and declining fertility, generated significant demographic challenges and it is now clear that these necessitate adjustments to the current Long-Term Care (LTC) system. Eurostat forecasts that the old-age dependency ratio will increase from 14 to 28 percent of the population by 2060 . The older the population will become, the greater will be the numbers of people who face difficulties with regards to their activities of daily living and the higher will be the incidence of dependency in the overall population.

Long-term care in Poland has been traditionally provided in an informal manner, predominantly by the family and predominantly by women. However, due to changes in the family structure, migration and female labor force participation patterns, informal family care no longer can continue to be the dominant form of care for people who need care. In response to the growing care needs of the population, formal care organized by the state or private institutions is progressively replacing traditional informal care provision, thus responding to the social needs that cannot be fulfilled within the family.

Currently, formal LTC in Poland is characterized by a fragmentation of responsibilities and lack of integration between the health and social sectors, both in terms of service provision and financing. The two systems are not coordinated around the needs of their patients and providers face incentives to "push" patients to the other part of the system ${ }^{2}$. In addition to the sectoral divisions, resources are distributed among national, provincial and gmina authorities, each executing its finances by administering its own programs. At the same time there is a rapidly developing and growing private for-profit and not-for-profit sector in Poland that offers various forms of LTC. Private entities operate in both the formal and the "grey" part of the market. Lack of regulation of private LTC activity as well as low quality of service provision are the two main constraints of the sector.

The current public spending level of LTC care in Poland is one of the lowest of the EU countries. In comparison to the EU average of 1.6 percent of GDP in 2016, public resources for the LTC sector amount to only 0.5 percent of Poland's GDP. About 56 percent of the benefits are provided in-kind and the remaining 44 percent in cash benefits. The low level of public spending results in significant co-payment on formal care services, large provision of care delivered informally and a growing sector of privately provided care. Families still cover most of the spending on LTC with 45 percent of the $65+$ population receiving informal family-based care.

To address these present challenges, this note recommends the following: (i) focus the short-term policies on strengthening the stewardship role of the government in LTC over public and private sectors while promoting the shift towards community care and home-based care, (ii) orient the medium-term policies on developing institutions to strengthen both intersectoral and level-of-government coordination of care, incentivize and promote the role of technology for managing and delivering LTC, while working towards ensuring adequate financing of LTC in a sustainable way.

Implementation of these policies will allow Poland to build a well-functioning market for elderly care services which supplies a continuum of high-quality care and where elderly in need of care and their families can find services that satisfy their needs and preferences, and the choices that they exercise are also based on their resource constraints.

\footnotetext{
${ }^{2}$ World Bank, 2018.
} 


\section{Introduction}

This note is prepared as a continuation of the long-standing collaboration between the Government of Poland and the World Bank in the area of Long-Term Care (LTC). Some of the earlier outputs of this collaboration include the 2009 report "Long-Term Care and Ageing" which examined the fiscal challenges arising from a growing need for LTC in the context of an aging society, and the 2015 report "the Present and Future of Long-Term Care in Ageing Poland", which outlined the key challenges and opportunities for developing a delivery and financing system for LTC for the elderly. More recently, the 2017 World Bank Technical Assistance (TA) culminated in the international conference "Long Term Care Systems Design and Financing" which focused the attention of policymakers and the international community on options for an integrated LTC system as well as demonstrating the fiscal and economic implications of adopting various LTC modalities. Importantly, the conference showcased the capacity of the World Bank to convene a broad range of stakeholders and to bring the latest know how to support this agenda.

The LTC agenda is receiving much attention in Poland's public debate. Rapid population ageing, a result of increasing longevity and declining fertility, generated significant demographic challenges and it is now clear that these necessitate adjustments to the current LTC system. Eurostat forecasts that the old-age dependency ratio will increase from 14 to 28 percent of the population by 2060. The older the population will become, the more people will face difficulties with regards to their activities of daily living and the higher will be the incidence of dependency in the overall population. This, in turn, spurs increases in the demand for various forms of care, both medical and social. Some of this demand is met by families through provision of familial care. However, informal care provision negatively affects earning and incomes of families and contributes to the overall labor shortage in the country. Continuous reforms are therefore needed, both in the health and social sectors, as well as in the labor market to meet these emerging needs.

\section{Supply of social care}

Just like in the rest of the world, long-term care in Poland has been traditionally provided in an informal manner, predominantly by the family and predominantly by women. However, due to changes in the family model and life-styles, informal family care is no longer the dominant form of care for dependent people. In response to the growing care needs of the population, formal care organized by the state or private institutions is progressively replacing traditional informal care provision, thus responding to the social needs that cannot be fulfilled within the family.

The supply (delivery and financing) of formal social care services is mainly the responsibility of municipality, called "gmina", with some institutional care organized by the higher level of local government, the district called "poviat". Both gminas and poviats are obligated by the central government to finance and provide social care services from their local budgets, covering institutional, community and home-based care, while the voivodeships (the authority representing the central government in local governments) has supervisory powers over institutional services provided by gminas and poviats. Financing of institutional (also called stationary) medical care services provided to eligible individuals is the responsibility of the National Health Fund, while the provision is organized by various providers (public and for- and non-for-profit private). On the other hand, financing for social care services stems from gminas' and poviats' social policy budgets (see Annex 1 for details.)

There is a vertical division of responsibilities at various institutional levels (national, regional and local). The supply of social care services is mainly the responsibility of municipality ("gmina"), with some institutional care organized by the higher level of local government, the district ("poviat"). Both gminas and poviat are required by the central government to finance and provide social services from their local budgets, covering institutional, community and home care, while voivodeships (the authority representing 
the central government at the local level) supervises the institutional services provided by gminas and poviat.

Although Poland has developed standards for some areas of care, overall quality standards remain underdeveloped. Poland, along with other EU countries, has put in place a licensing system for providers in order to better monitor quality of care. Furthermore, the country has established quality standards for residential care institutions over three main domains: employment, procedures and accommodation standards, separately for the health and social sector ${ }^{3}$. In the health sector, standards are clearly established and are a contractual requirement. However, in the social care sector, with the exception of residential care, standards are barely established.

Poland has cash and in-kind benefits for elderly care and these are briefly described below. (Annex 1 contains further information).

\section{Cash benefits}

Cash benefits are available to supplement in-kind care. The most common cash benefit is the care supplement, which is a monthly cash grant (PLN 207) given universally to all persons aged 75 or over who are entitled to a retirement pension. The benefit is financed by the social insurance scheme. Persons who are not entitled to the care supplement due to a lack of social insurance are entitled to the nursing benefit (PLN 153 per month), which is part of the family benefit system, financed by the resources of local authorities ${ }^{4}$.

There is an additional benefit for families where the caregiver of the care-dependent person resigns from employment to take care of the dependent relative. This special nursing allowance is a monthly cash grant of PLN 250. One of its eligibility conditions is that the care-dependent person does not receive a pension.

\section{Home care}

Home-based care takes two forms: (i) nurses visiting patients' homes to perform medical services, or (ii) caregivers visiting patients' homes to assist them with ADLs and IADLs. Access to nurses' services provided by the health sector is based on an assessment of health needs. The visits are covered by the National Health Fund across the country. Services provided in the social sector can be obtained through the gmina's social welfare center and are mainly awarded to low-income elderly and other vulnerable households. Furthermore, provision of social services depends on the gmina's social care budget and varies widely between municipalities with large cities providing the most services. Some municipalities also provide home refurbishing grants to frail elderly.

Home-based services have started to develop only recently, and their availability and quality depends on the level of funding the Gmina can afford to provide for these services. As a result, home-based care is mainly available in more developed municipalities and cities, whereas poorer municipalities often cannot afford service provision, thus effectively outsourcing these tasks to familial caregivers.

\section{Community care}

Community-based care services are provided in specialized community care centers, managed either by local authorities or NGOs, or in special rooms in DPS or ZOL. Community care remains generally underdeveloped. Shortages of accessible community care lead to significant inefficiencies throughout the

\footnotetext{
${ }^{3}$ European Commission, 2018.

${ }^{4}$ European Commission, 2018.
} 
system and reduce consumer satisfaction, as daycare centers can provide an intermediate form of care that is more user-friendly than institutional facilities. The lack of community care also prevents many dependent elderly people living alone or with their families from continuing to live at home, as the availability of daycare services may allow some types of patients to stay longer at home and thus reduce the need for institutionalization, which remains costly.

\section{Institutional care}

Institutional care is split between the health sector and social assistance sector. In Poland, institutional care, provided by the public sector and available for the frail elderly is of two types: social homes (DPS) which receive funding from the gmina and poviat, and medical rehabilitation homes (ZOL) which receive funding from the National Health Fund. There are roughly 500 ZOL and ZPO, not counting the 150 hospices and palliative care.

Eligibility for a place in a ZOL is based on the severity of need measured by a Barthel Scale assessment conducted by a physician or nurse in an institution, and individuals who score less than 40 points may be included in a queue for a place in a ZOL (if this is their first assessment) or "jump the queue" and obtain a stay in an institution (in the event of repeated assessment). ${ }^{5}$ The stay in ZOL was previously limited to 6 months, but this provision was abandoned in 2007, which led to a virtual redevelopment of ZOLs from rehabilitation centers to care facilities where elderly patients tend to stay forever.

In the social sector, eligibility for a place in a DPS is based on an assessment by a social worker that takes into account the person's condition (frailty, dependency) as well as the ability of the patient's family to provide care. There are about 86,000 residents in DPS. The creation of ZOLs- has reduced the average length of stay in Polish hospitals and improved access to hospitals. ${ }^{6}$

Financing rules and eligibility criteria result in rationing of institutional care. Indeed, the gmina authorities are encouraged to qualify their dependent elderly people for ZOLs instead of DPSs in order to reduce their budgetary pressure ${ }^{7}$. Similarly, ZOL managers, who face a predetermined reimbursement rate per patient, are encouraged to skim and refuse patients who require labor intensive care. At the same time, although the ZOL system seems to offer good quality services, bed availability is very limited. ZOLs' primary mission of providing rehabilitation services cannot be accomplished because most beds are occupied by frail elderly who would be better placed in long-term residential care facilities.

Overall, institutional care is expensive for national and local authorities as well as for the affected individuals. Nevertheless, both ZOL and DPS facilities have long waiting lists as the density of beds in residential health care facilities is among the lowest in OECD countries, with less than 20 beds per 1000 inhabitants aged 65 and over (OECD 2014). ${ }^{8}$ As outlined above, the lack of residential care in Poland leads to an ineffective use of healthcare provisions as extended stay in hospital awaiting to be discharged have emerged (see Annex 1 for further details). ${ }^{9}$ There are also significant regional differences in the provision of long-term residential care. The largest number of beneficiaries of nursing and residential care in ZOL and ZPO and stationary residential care in DPS are in southern and central Poland. ${ }^{10}$ Moreover, there are

\footnotetext{
${ }^{5}$ World Bank, Poland: Options for Better Quality and More Accessible Long-Term Care Services for the Elderly in Poland 2018.

${ }^{6}$ Central Statistical Office of Poland (GUS), 2017.

${ }^{7}$ World Bank, 2018.

${ }^{8}$ Work Bank, The present and future of long-term care in ageing Poland, 2015.

${ }^{9}$ European Commission, 2018.

${ }^{10}$ World Bank, 2015.
} 
huge variations in the quality of the DPS system - DPSs that are managed by wealthier municipalities provide good quality services, while others do not (see Annex 1, figures 4 and 5).

\section{Coordination of care across health and social ministries, and across local and central authorities}

LTC in Poland is characterized by a fragmentation of responsibilities and lack of integration between the health and social sectors, both in terms of service provision and financing. The two systems are not coordinated around people's needs and providers face incentives to transfer patients to the other part of the system $^{11}$. In addition to the sectoral divisions, resources are distributed among national, provincial and gmina authorities, each executing its finances by administering its own programs.

This lack of coordination has resulted in a patchwork of programs that do not correspond to a coherent system of care where solutions are often either duplicated or non-existent. The proliferation of programs and initiatives, combined with weak information systems, often leaves seniors and their families unaware of the solutions available and what they are eligible for. As a result, frail elderly people and their guardians often choose the primary care options available, which tend to be expensive, or waive coverage.

Many stakeholders point to duplication, waste of resources and misallocation - mostly because resources are not directed towards the areas which are most cost-effective, namely home- and community-based care. A graph in Annex 2 describes Polish LTC system from the standpoint of an individual. Overall, there is every reason to believe that sector integration would lead to significant efficiency gains. Denmark, Ireland and Portugal all have LTC systems in which health and social care are organized in a horizontal way, incentivizing better cross-sectoral collaboration. ${ }^{12}$

\section{Financing of care}

The current public spending level of LTC care in Poland is one of the lowest of the EU countries. In comparison to the EU average of 1.6 percent of GDP in 2016, public resources for the LTC sector amount to only 0.5 percent of Polish GDP (see Annex 2). About 56 percent of the benefits are provided in-kind and the remaining 44 percent in cash benefits. The low level of public spending results in significant co-payment on formal care services, large provision of care delivered informally and a growing sector of privately provided care. Families still cover most of the spending on LTC with 45 percent of the 65+ population receiving informal family-based care.

Given the current institutional setup, public spending on LTC is likely to increase in the future. According to the Ageing Working Group (2018), public spending is expected to rise from $0.5 \%$ to $1.3 \%$ of GDP by 2070 in the LTC Polish sector, implying an increase of 166\%. The rise of public expenditure could put pressure on the long-term sustainability of public finances.

Although financial responsibilities match the organizational structures of the supply of LTC care, the present allocation of public resources produces spatial inequalities in providing supply of institutional LTC care. Financing of social services, including home-based care, community-care, and social welfare homes, are the responsibility of the gminas whereas health services are financed through reimbursements from the NHF. Gminas receive limited earmarked funding from the central government but the availability of social

\footnotetext{
${ }^{11}$ World Bank, 2018.

${ }^{12}$ European Commission, 2018.
} 
services mainly relies on the gminas' contributions from their budget, particularly in rural areas where care provision levels are low.

Furthermore, although the central government level provides Gminas with limited grants for the creation of new or the adaptation of existing facilities, uptake is often low as Gmina authorities fear that they would have to take over the funding of such facilities once central funding runs out. A similar problem also applies to EU-funded programs as many municipalities predict that they will have to discontinue these services once EU funds run out as there are no alternative funding sources.

Within the institutional care sector, patients of institutional facilities are required to co-pay about 70 percent of their pension or wage income for custodial care, with exemptions made for very poor individuals. However, as pension benefits and wage incomes of most seniors in need of care are low, co-payments cannot cover the actual cost of staying in a DPS or ZOL ${ }^{13}$, which results in these facilities facing permanent revenue shortfalls. In the case of community care and home-based care, funds stem mostly from Gminas' limited budgets or ad-hoc sources such as EU social funds.

\section{Private Sector engagement in care provision}

There is a rapidly developing and growing private for-profit and not-for-profit sector in Poland that offers various forms of LTC. Private entities operate in both the formal and the grey part of the market (mostly home-care providers). A typical grey market provider would be a for-profit operator that operates residential care facilities with 10 to 25 beds in private apartments or private homes. These suppliers generally do not apply for registration as their premises do not meet regulatory standards for construction, accessibility or health codes and they do not meet an inspection. A typical supplier in the high-end formal sector of the market would be a for-profit or not-for-profit operator operating a stationary facility or a retirement community whose income depends on direct patient payments. ${ }^{14}$ In general, formal private sector institutions also provide medical services on their premises, provided by NHF-funded doctors and nurses.

There are two main types of formal sector private facilities that are mainly located in major metropolitan cities and offer a wide variety of services. First, private non-profit organizations, often NGOs, which operate long-term medical care facilities (ZOL-type) with approximately 50 to 100 beds. Secondly, social service providers registered as for-profit private companies under the "Law on Economic Freedom" provide institutional care (DPS type) and charge about 3,000 to 4,000 pln per month. Furthermore, private providers have also started entering the home care market (with an hourly rate of about PLN 15 to 30), but the formal provision of these services is limited by regulation (for example, some medical procedures cannot be performed in patients' homes).

Lack of regulation of private LTC activity as well as low quality of service provision are the two main constraints of the sector. While standards for ZOLs and DPSs are clearly defined, private social service providers registered under the "Law on Economic Freedom " operate in a vacuum with respect to regulations guiding quality standards for social care. Multiple reports, however, suggest that their number is increasing, which clearly indicates a growing demand for their services. For example, a recent World bank Regional Health Spending Review indicates that underdeveloped public LTC services in the Wejherowksi region result in a growing sector of privately provided care. Some of these facilities operate without registration and in the grey market, raising serious concerns on the quality of services provided. ${ }^{15}$

\footnotetext{
13 These amount to about 3,500-4000 pln and 5,000-5,500 pln per person per month, respectively.

${ }^{14}$ World Bank (2018).

${ }^{15}$ World Bank (2018): Regional Health Sector Public spending review
} 
The marketization and privatization of LTC is a long-term trend in many EU countries ${ }^{16}$ (see Annex 3 for a description of selected counties.) In the United Kingdom, private for-profit and non-profit institutions have developed as a result of government policy choices to increase competition and create a market for LTC provision. In other countries, such as Belgium, Denmark, France, private non-profit and for-profit LTC institutions can compete for public funding. Furthermore, some countries (e.g. Finland) give earmarked vouchers to care-dependent citizens that can be used for the purchasing of care from private providers. Last, in countries with serious shortages of formal state-provided care (e.g. Hungary, Romania), a private commercial sector has emerged independently offering care to dependent people who can afford to pay themselves.

\section{Human resources for medical and social care}

The gap between increasing demand for LTC and the supply of qualified caregivers and nurses will expand in the long-term as the country's demographics are shifting. According to forecasts, the demand for LTC professionals will increase by 54 percent for home care professionals and by 38 percent for residential care professionals by $2030^{17}$

The existing lack of employees in medical and social care in Poland is noticeable in cities, but it is even more evident in rural areas, due to high levels of outmigration of young generations both to metropolitan areas within Poland as well as Western European countries such as Germany or the United Kingdom. A perception of poor working conditions and low salaries in the sector disincentivize many Polish caretakers and nurses to stay in the country. This phenomenon is further exacerbated for employees in the home-based care sector where low wages without benefits on short-term contracts create a sense of weak job security.

Poland is currently relying on migrant caregivers, mostly from Ukraine and Belarus. However, as Germany will open its market to caregivers form these countries in 2019, many stakeholders expect a widespread of outflow of Ukrainian and Belarusian migrants in search for higher wages. Furthermore, many migrant caregivers currently work informally in the grey economy. ${ }^{18}$

Many of the informal caregivers in Poland lack adequate training and have no access to resources to assist their caregiving activities. Moreover, according to a recent study of informal care in Poland, many informal caregivers themselves suffer from poor health, anxiety, and a lack of access to respite care ${ }^{19}$. These factors exacerbate the dampening effect on female labor force participation that caregiving responsibilities entail.

\section{Technology}

Multiple reports indicate that there is an untapped potential to use technology for delivering LTC and there is significant room for improvement. The division of responsibilities within the system potentially creates institutional disincentives to introduce technology as it is unclear who is responsible for championing initiatives to increase the use of technology.

There are some local government initiatives aimed at increasing the use of technology. For example, the city of Warsaw is testing the use of devices (such as NFC stickers to check-in/out and monitor caretakers through their smartphones) to monitor the quality of home-care services. Furthermore, the city of Torun is piloting a website that provides a comprehensive database of both public and private LTC suppliers, thus creating transparency and enhancing seniors' access to information. There are also several initiatives at the

\footnotetext{
${ }^{16}$ European Commission, 2018.

${ }^{17}$ Golinowska, Kocot, Sowa, 2014.

${ }^{18}$ Golinowska, Sowa, 2017.

${ }^{19}$ Luczak, 2017.
} 
local level which aim at increasing elderly citizens' mobility to allow them to live independently. Last, the Ministry's of Health "Digital Poland 2014-2020" initiative, aiming to improve e-services in healthcare, has potential applications in LTC.

\section{Recent government initiatives}

Elderly care is high on the agenda of the National as well as local governments and receives much attention in the public debate. There are currently many ongoing initiatives to improve LTC in Poland.

First, the ongoing program "Opieka 75+", financed by the central government, provides funds to small municipalities to finance social workers taking care of elderly citizens living alone at home. However, early feedback indicates that the program's uptake is low as the funds are too strictly earmarked. The program is also limited to very small municipalities, further reducing accessibility of this funding source.

Second, the government is in the process of implementing its "Senior-WIGOR" program. This initiative subsidizes the activities of local governments to develop daycare centers with additional funding being given to low income municipalities or those with a high proportion of care-dependent elderly. The initiative has a total fiscal envelope of $€ 370$ million over the period $2015-2020^{20}$.

Third, the National Development Council is preparing a major new initiative on LTC for people over 75 years of age, in the form of a presidential legislative initiative. This initiative responds to the clear need to improve coordination between health and social care systems. The core of the initiative is to introduce new poviat-level coordination centers that will be the point of access for older people and their families and will manage triage in the social and health care systems. The initiative addresses the fundamental need for coordination. However, there are concerns how the newly established institutions will interact with existing programs and which department will be responsible for implementation. ${ }^{21}$

In addition, the Ministry of Health launched a national survey of elderly citizens, "Polsenior 2", in September 2018 to gain comprehensive and interdisciplinary insights on the population of persons aged 60 and over in Poland. The study is a continuation of the "Polsenior 1" study, conducted 10 years ago, and aims to inform the design of policy reforms of the health care system. ${ }^{22}$

\section{Policy options}

This section outlines a set of policy options for the short- and medium- terms. The short-term options are focused on strengthening the stewardship role of the government in LTC while promoting the shift towards community care and home-based care and the development of private sector care provision. The mediumterm options are focused on building institutions for strengthening both intersectoral and level-ofgovernment coordination as well as promoting the role of technology for managing and delivering LTC, while weighing options to ensuring adequate and sustainable financing for LTC. Implementation of these policies will allow Poland to build a well-functioning market for elderly care services which supplies a continuum of high-quality care and where elderly in need of care and their families can find services that satisfy their needs and preferences, and the choices that they exercise are also based on their resource constraints.

\footnotetext{
${ }^{20}$ European Commission Joint Report on Health Care and Long-Term Care Systems and Fiscal Sustainability-

${ }^{21}$ World Bank, 2018.

${ }^{22}$ Ministry of Health, Poland, 2019.
} 


\section{Options for short-term}

- Creating incentives to shift both supply and demand of LTC from institutional care to community and home-based care. This could be achieved through the expansion of ongoing initiatives such as the Opieka 75+ program. Strengthening institutions in charge of develop quality standards, accreditation and control procedures for community and home-based care would also be a step in the right direction.

- Supporting familial carers. As most LTC is currently provided by familial caregivers, policies that provide counseling and information to informal caregivers and give them access to respite care are likely to have a positive impact on their welfare. They would also mitigate the incidence of physical and mental health problems among caregivers. The entry point for implementation of such polices could be the new poviat-level coordination centers.

- Fine-tuning the design of cash benefits to make sure they do not pose disincentives to labor market participation, especially for women. Bargu and Morgandi (2019), using the OECD tax-benefit model, show that the current system generates negative incentives stemming from the design of cash benefits.

- Establishing a poviat-level database to share regional policy initiatives in LTC. Several regions are conducting policy experiments initiatives to enhance the supply and quality of LTC. However, these initiatives are not shared between regions and cannot be used as guides or good practices in implementing LTC policy. An online database shared by poviats would substantially boost the policymaking process within the LTC sector.

- Undertaking data-gathering efforts to better understand the private sector's current role in the provision of LTC. The aim would be to better understand the decision-making processes (on the side of consumers) and cost structure (on the side of providers) as well as determinants of quality, pricing strategies etc. This could be followed by the development of an IT system to collect information from all types of providers in order to harmonize the supply of services for the elderly across public and private, national and local, medical and social dichotomies, as well as home, community and stationary facilities.

- Encouraging the development of the LTC private sector, both for-profit and non-profit. Two prior actions - understanding the characteristic and "production function" of private providers and strengthen the stewardship capacities of the government would pave the way for further encouragement of the private sector in LTC provision. Privately provided LTC would help ease the constraints on public finances, mitigate public supply of services limitation, and address the growing demand of LTC care. The private sector could be supported through various forms of public-private partnerships at a national and regional level. A stronger involvement of NGOs, especially in the areas of hospice care provision, community care and home-based care and civil society at a local level should also be fostered.

\section{Options for medium-term}

- Enhancing coordination between different stakeholders in the LTC system. This is especially important in case of coordination between the central government and the local governments, and across the medical and social sectors. Recent government initiatives to foster coordination could be evaluated, and the ones that are successful - scaled up. The new poviat-level coordination centers could provide a focal point for LTC users. Furthermore, the use of shared technology (databases, 
online services) would facilitate the integration across different levels. Mitigating the fragmentation within the LTC sector would not only improve the efficiency of public resources' allocation, but also increase quality of care provision and patients' satisfaction.

- Increasing the use of technology in LTC provision. Allocative efficiency of LTC funding could be enhanced through giving consumers and providers access to information websites and databases. Technology in a form of assistive devices and barrier-free access would also allow dependent seniors to live autonomously at home for longer. The "Digital Poland 14-20" program provides an excellent platform for taking these initiatives forward.

- Developing LTC human resources for both medical and social care. A decision needs to be taken whether Poland wants to incentivize migration of care workers from non-European countries. At the same time, incentivizing Polish retiree to perform part-time care work could be an effective solution to increase the supply of LTC workers. Investments in the educational sector's capacities to train more long-term care workers are also needed.

- Implementing measures to increase disease prevention in childhood and to promote healthy living in adulthood. Encouraging heathy and active lifestyles and thus preventing care-dependency in oldage for as long as possible is the most cost-effective measure to reduce LTC demand. The Epibaza project by the National Institute of Public Health, aimed at the early detection of morbidity patterns, is an important first step in this direction. Furthermore, policies aimed at reducing the incidence of smoking and obesity would also reduce pressure on the LTC system.

- Creating underpinnings for financial sustainability of LTC system. To keep financing needs low, the delivery system needs to shift to home and community to the greatest extent possible. Promotion of healthy ageing, shifting LTC burdens from medical towards social services, and the development of a private LTC market would all contain cost pressures. Identifying additional financing streams (i.e. sin taxes, welfare lottery, etc.) could also be considered. 


\section{ANNEX}

Annex 1: Organization of long-term care services in Poland ${ }^{23}$

Figure 1: Organization of LTC in Poland

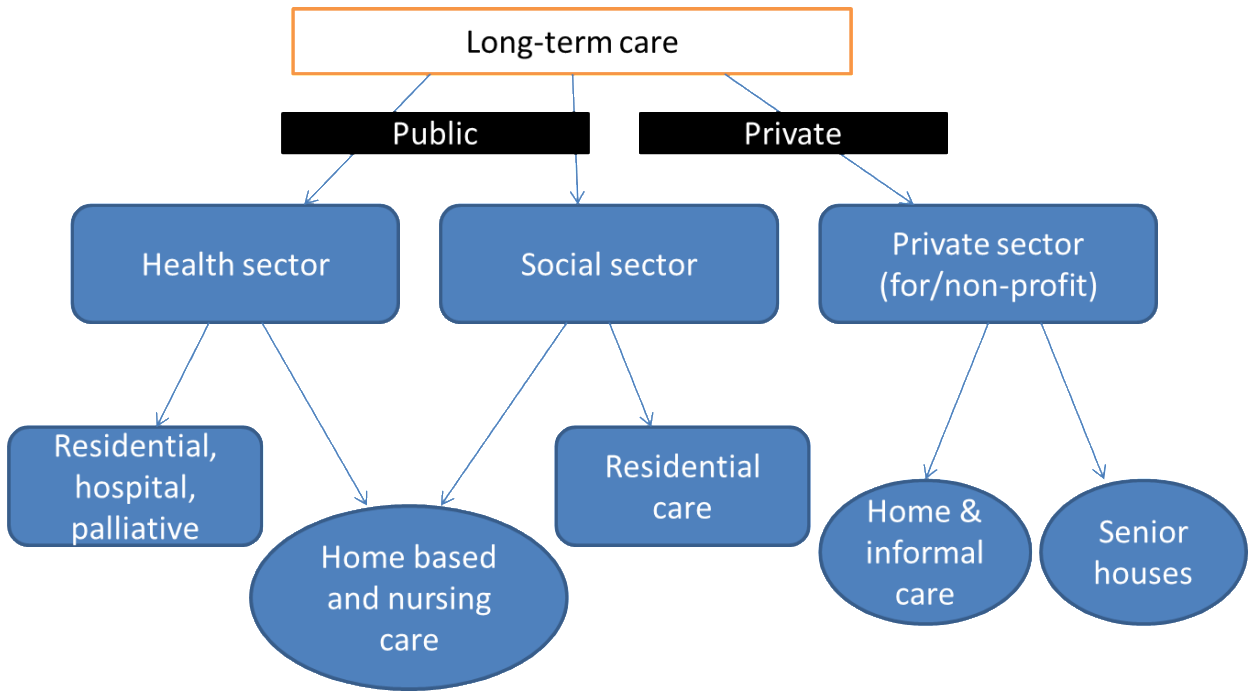

Figure 2: Overview of services and benefits related to long-term care ${ }^{24}$

\begin{tabular}{|l|l|l|l|}
\hline & Health sector & $\begin{array}{l}\text { Social assistance/ } \\
\text { Family benefits }\end{array}$ & Social security \\
\hline $\begin{array}{l}\text { Residential } \\
\text { care }\end{array}$ & $\begin{array}{l}\text { Care facilities } \\
\text { (ZOL, ZPO), } \\
\text { hospices, and } \\
\text { palliative care } \\
\text { units }\end{array}$ & Social assistance homes (DPS) & - \\
\hline Day care & -- & Day care centers & - \\
\hline $\begin{array}{l}\text { Social } \\
\text { services }\end{array}$ & $\begin{array}{l}\text { Assisted living } \\
\text { facilities }\end{array}$ & $\begin{array}{l}\text { Home services and specialized } \\
\text { home services }\end{array}$ & - \\
\hline $\begin{array}{l}\text { Cash } \\
\text { benefits }\end{array}$ & - & $\begin{array}{l}\text { Nursing benefit (zasilek } \\
\text { pielęgnacyjny) to caregivers of } \\
\text { disabled children and people } \\
75+(153 \text { PLN/month) } \\
\text { Nursing allowance } \\
\text { (swiadczenie pielegnacyjne) } \\
\text { for full-time caregivers of } \\
\text { disabled child (1200 } \\
\text { PLN/month) or special care } \\
\text { allowance for families with a } \\
\text { disabled child, which fulfill } \\
\text { the income criterion for family } \\
\text { benefits (520 PLN/month)* }\end{array}$ & $\begin{array}{l}\text { (dodatek } \\
\text { universal benefit to } \\
\text { (206.76 } \\
\text { PLNonth) }\end{array}$ \\
\hline
\end{tabular}

*amounts in 2015

Source: Authors' own compilation based on the website of the Ministry of Labor and Social Policy (www.mpips.gov.pl)

${ }^{23}$ Work Bank, The present and future of long-term care in ageing Poland, 2015.

${ }^{24}$ Ibid 
Figure 3: Average Length of stay in hospitals by age in selected European countries $(2011)^{25}$

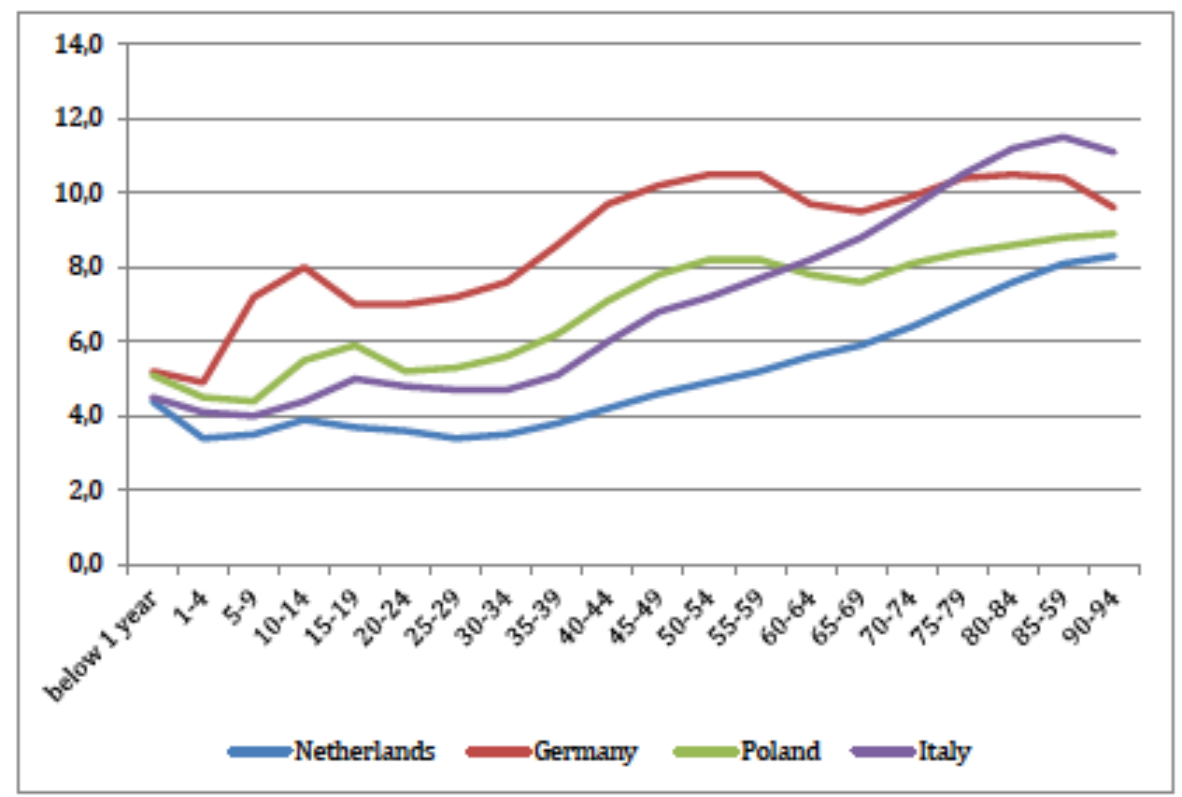

Figure 4: Regional differentiation in provision of residential long-term care for adult population in $\mathrm{ZOL}$ and $\mathrm{ZPO}^{26}$ in $\mathrm{DPS}^{27}$
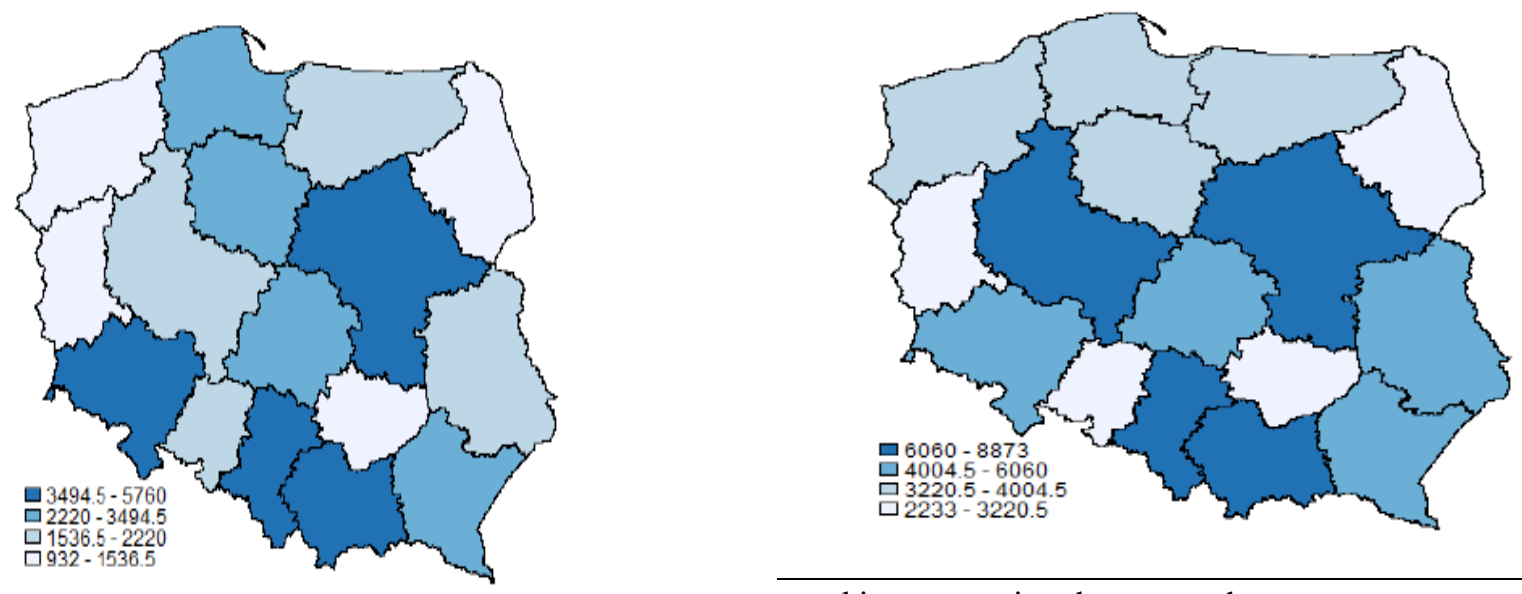

, making any major changes to the system.

25 Ibid.

${ }^{26}$ Work Bank, The present and future of long-term care in ageing Poland, 2015.

27 Ibid. 
Annex 2: Financing of LTC in Poland and other EU countires

Figure 5: Long-term care health expenditure in 2015 in the $\mathrm{EU}^{28}$

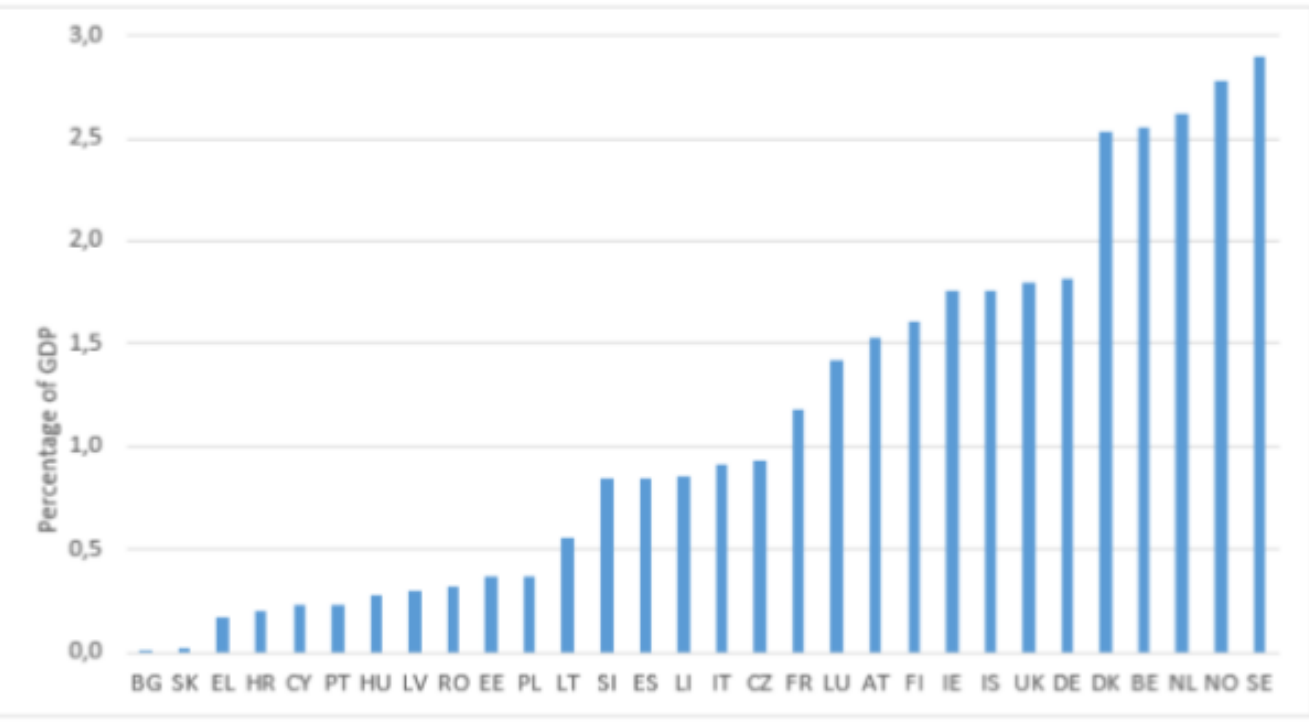

Figure 6: Long-term care social expenditure in 2015 in the $\mathrm{EU}^{29}$

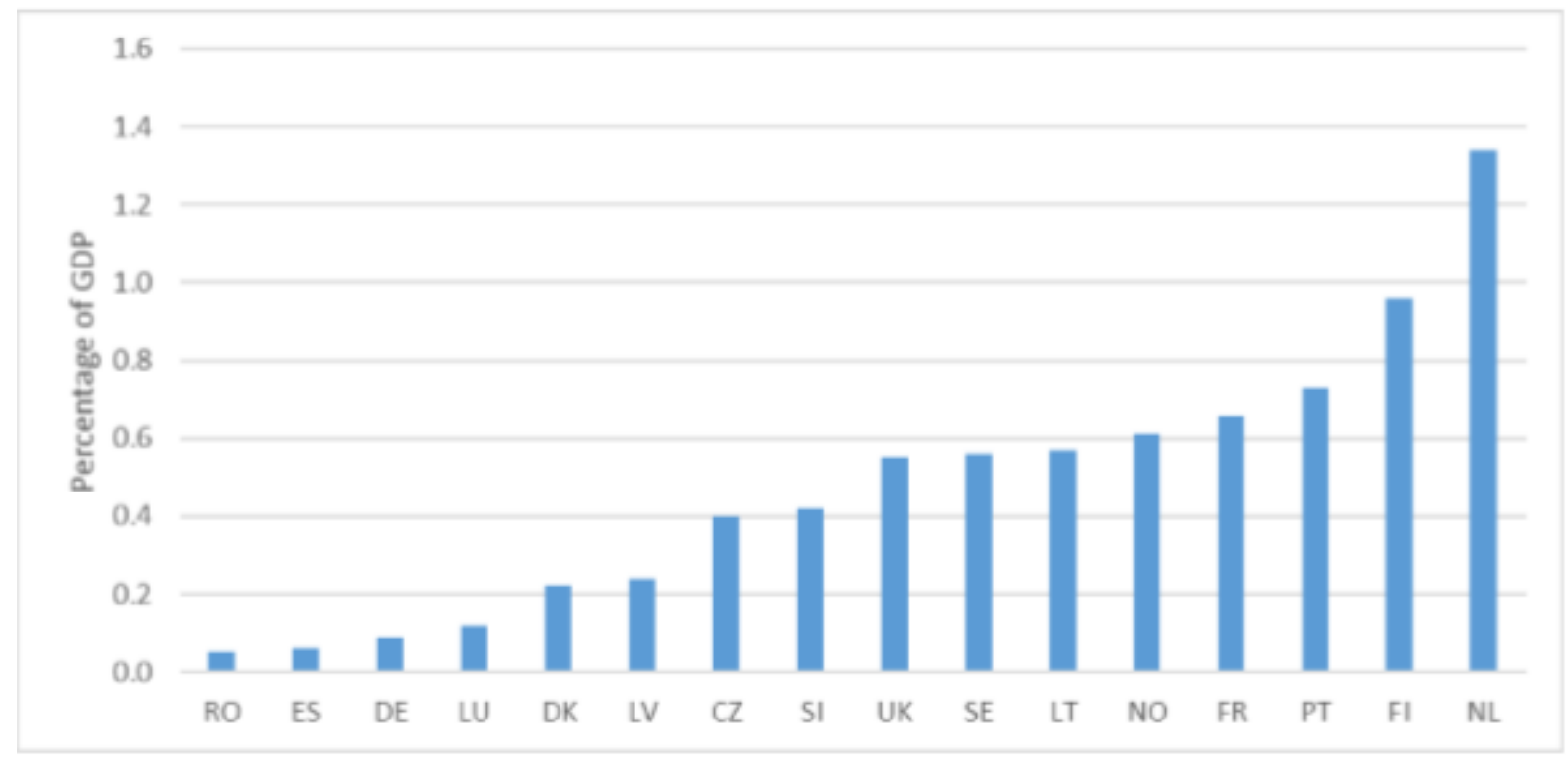

${ }^{28}$ European Commission, Challenge in Long-term care, a study of national policies, 2018.

${ }^{29}$ Ibid 
Figure 7: Long-term-care expenditures as a share of the total health expenditures in Poland ${ }^{30}$

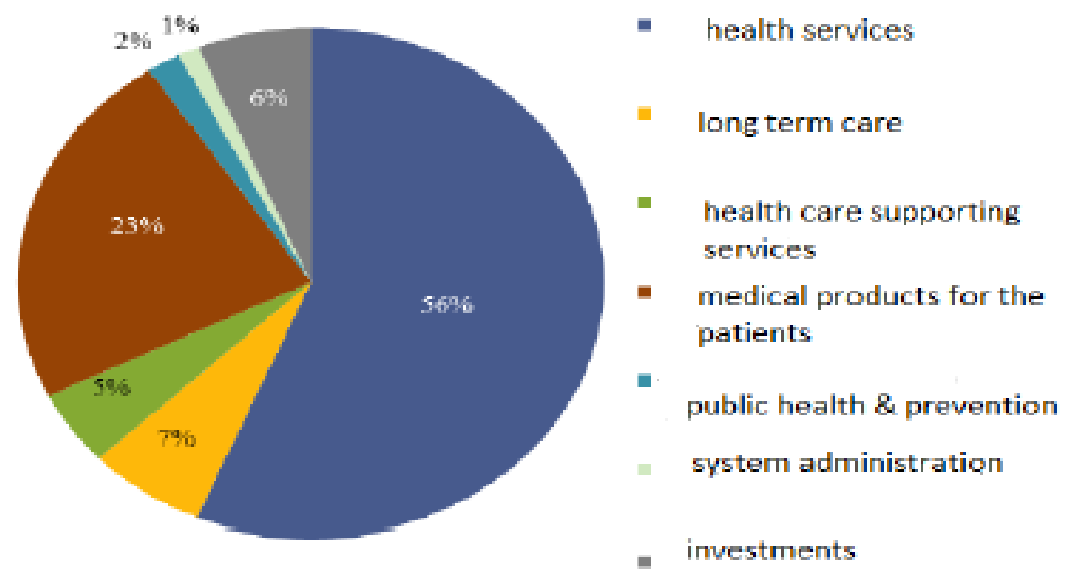

Figure 8: Financial flows in the long-term care in Poland ${ }^{31}$

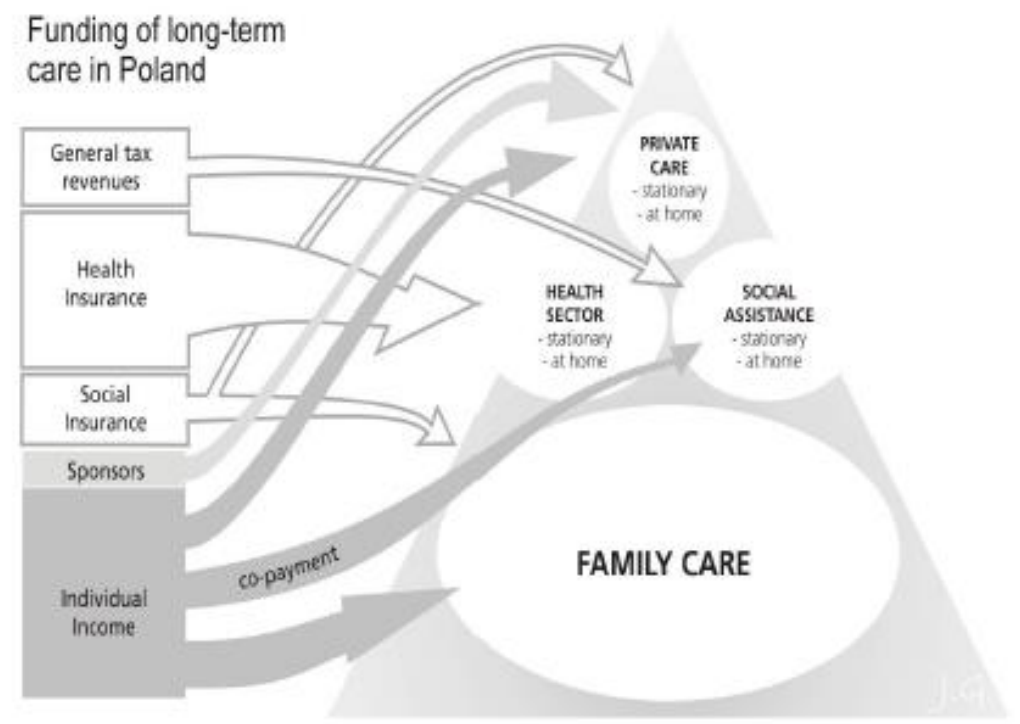

${ }^{30}$ Work Bank, The present and future of long-term care in ageing Poland, 2015.

${ }^{31}$ Work Bank, The present and future of long-term care in ageing Poland, 2015. 
Figure 9: Projection of long-term care expenditures in million PLN 2012-2060 ${ }^{32}$

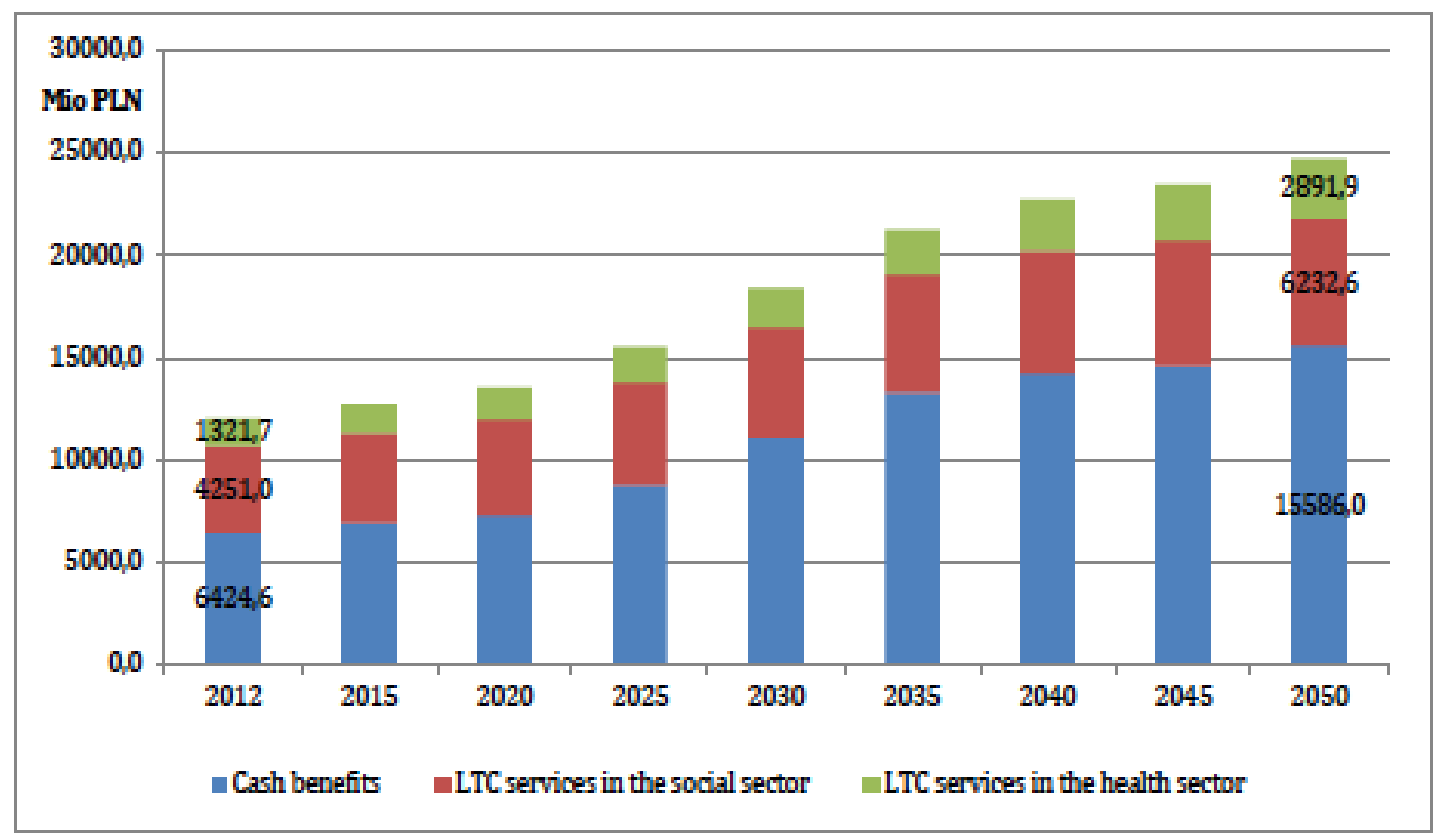

Figure 10: Projections of long-term care expenditures in relation to the GDP 2013-2060 33

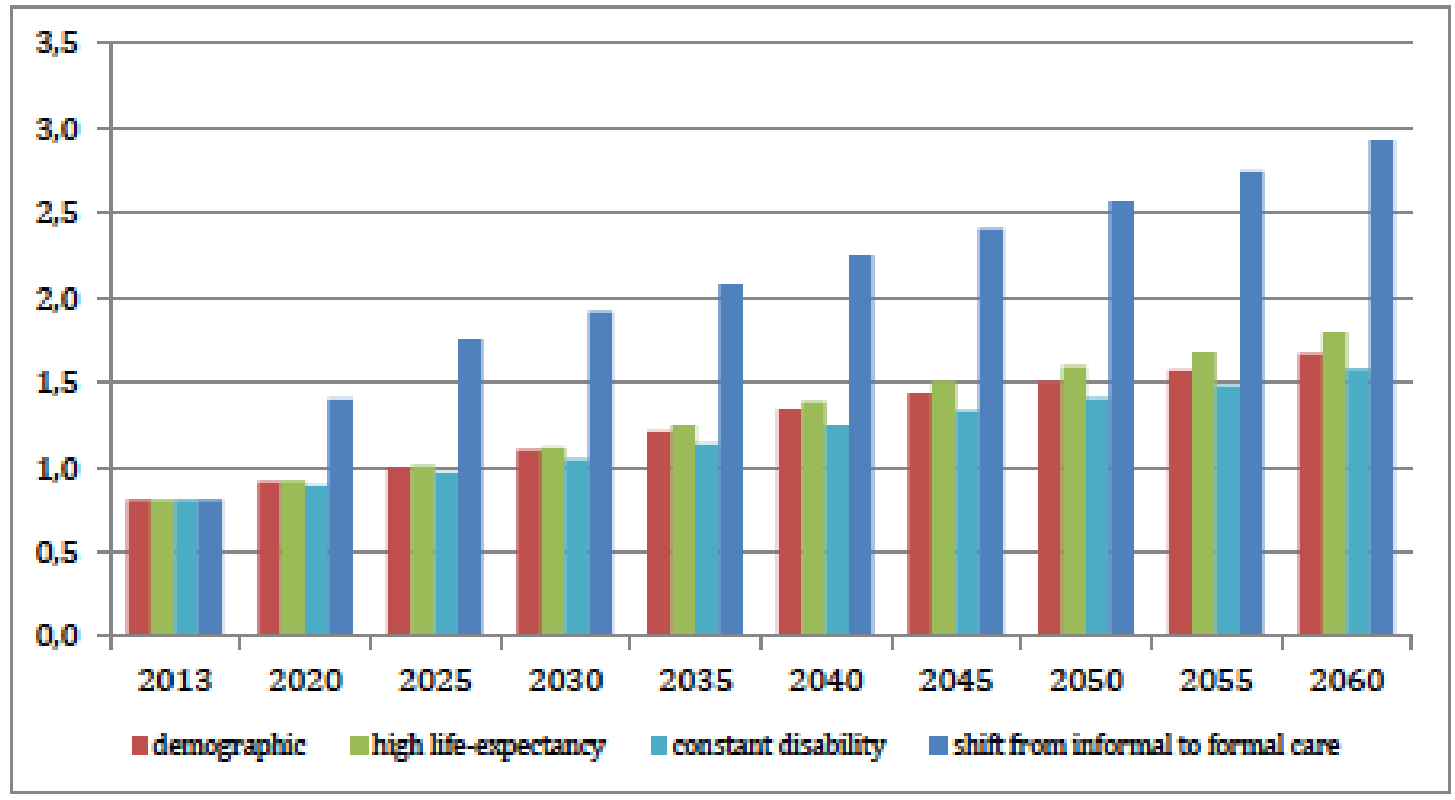

${ }^{32}$ Ibid.

${ }^{33}$ Work Bank, The present and future of long-term care in ageing Poland, 2015. 


\section{Annex 3: Some international comparisons of LTC systems}

\section{United Kingdom ${ }^{34}$}

In the UK, most social services are purchased by the private sector or informally provided by families. The United Kingdom's total annual expenditure on social protection exceeds $£ 16$ billion (EUR 22.83 billion). Total expenditure on health and health-related social care represents $9.9 \%$ of GDP, a level similar to the EU-14 average. Legal responsibility for funding and social policy is vested in the four countries of the United Kingdom. Funding comes from national income and local domestic and commercial property taxes. Commissioning services, assessing potential users and determining eligibility are essential responsibilities of local authorities in each country. Individuals make a significant contribution to total social spending. In England, those with assets above $£ 23,250$ (EUR 26,500) pay the full cost of institutionalization; below $£ 14,240$ (EUR 16,274), local authorities pay the full cost (within these upper and lower limits, costs are distributed).

Local authorities are legally responsible for assessing individual and population-level care needs and ensuring that appropriate support is available, in a residential setting or at home or from family carers. Local authorities have considerable discretion in terms of eligibility and supply; despite some standardization of assessment processes and eligibility thresholds, service levels and models vary from one locality to another. DWP care and caregiver benefits are allocated under separate eligibility and assessment agreements across the United Kingdom.

Inadequate social services are increasing pressure on the NHS and family carers due to budget cuts. In England in particular, the viability and capacity of residential care providers and community-based/domestic care providers, as well as the quality of services, are under serious threat. Caregivers have difficulty recruiting, training and retaining staff while facing significant increases in the wage bill. They therefore withdraw from local authority contracts and/or focus on private buyers who may be charged higher fees.

In England, since the early 1990s, social care has developed into a quasi-market dominated by for-profit and charitable providers funded by local authorities; $89 \%$ of home services and $94 \%$ of residential beds for the elderly are provided by private providers; the residential market in particular is dominated by several large chains supported by private capital and dependent on high-risk financial structures.

Romania $^{35}$

From 2011, when long-term care (LTC) was first defined in Romanian legislation (Law L292/2011 on Social Assistance), a series of positive developments were initiated. Unfortunately, LTC in Romania is still dispersed between different sectors (health, social assistance, social protection for people with disabilities, social protection of children's rights, pensions) and the responsibility for organising and financing LTC services is shared between different ministries, national agencies and administrative levels (national, departmental or local). Overall, the benefits and services for the different groups in need of LTC fall under social assistance policies (in the case of frail elderly people), social protection for people with disabilities, the public pension system (in the case of disabled pensioners), and the health system (in the case of the chronically ill).

The fragmentation of responsibilities and programs, in the absence of effective coordination between sectors, agencies and administrative levels, has led over the years to a series of overlapping measures (due to a dual system of functional assessment, for disability and handicap), insufficient coverage, uneven and unpredictable developments, and lack of sustainability/stability of funding.

The LTC system in Romania, like the entire social protection system, is biased towards monetary benefits, with a deficit in social services, and in particular those aimed at supporting independent living and deinstitutionalization (i.e. rehabilitation, social integration and preventive health services). Thus, while the degree of institutionalization is relatively low among the dependent population ( $2.5 \%$ for people with disabilities, $0.4 \%$ for the elderly), demand for residential services remains very high in relation to supply, due to the low volume of non-residential services provided (in 2016, only $0.3 \%$ of people with disabilities living with their families were covered by non-residential services). Most residential centers are traditionally located in rural areas (and maintained from local budgets) while nonresidential services are provided in large cities. Caregivers are mostly employed informally, although there is a legal

\footnotetext{
34 Source: ESPN Thematic Report on Challenges in long-term care, United Kingdom 2018
}

${ }^{35}$ Source: ESPN Thematic Report on Challenges in long-term care, Romania 2018 
system allowing severely disabled people to opt for a formally employed caregiver or an equivalent allowance (covering, in principle, $38 \%$ of the total number of accredited disabled people).

Most of these uneven developments are due to the fact that the financing of almost all social services, including residential centers, has been gradually decentralized over the past 15 years (while more than $90 \%$ of local authorities are located in rural areas, with extremely low capacity to raise funds even for their own administration). As a result, a very high proportion of recently developed social assistance and non-residential services are located in large cities or county towns of residence, with residential centers condemned to underfunding. It is impossible to estimate total spending on LTC, but social assistance services are systematically underfunded.

France $^{36}$

Dependency recently identified as a risk to be covered by social protection. At the end of the 1990s, the public effort focused both on improving the supply of services (creation of retirement homes) and on making demand more solvent (creation of the personalized autonomy allowance- APA). Managed at the local level by the department, APA is paid, at home or in an institution, to any person aged 60 or over who needs help to carry out their daily activities. At home, it finances a specific "care plan" developed with a multidisciplinary team of professionals and covers needs that are not covered by the health insurance system. Total public and private expenditure related to dependency estimated at $€ 28.3$ billion.

Traditionally characterized by a familyist approach to care for the elderly, France has evolved towards a mixed model, combining public and family care. Long-term care (LTC) is a fragmented policy area involving different levels of governance and several institutional, organizational and professional actors.

Various services in kind have been set up since the 1970s (home care services, residential care) to provide care for the elderly. However, given demographic trends - by 2060, one third of the French population will be over 60 years old, including nearly 5 million people over 85 years old compared to 1.4 million in 2015 - these measures are insufficient. In a context of expenditure reduction, the sustainability of public finances is a major challenge.

Different solutions have been adopted in recent decades to address current challenges and anticipate the demographic situation in the future.

Since the 2010's, more emphasis has been placed on the role of informal caregivers. Home-based care, which is considered the cheapest option, cannot develop without an informal caregiver acting as a coordinator of the organization of care. Policy measures to support informal carers have been introduced to facilitate investment in informal carers: care leave, respite solutions, training and education.

$\rightarrow$ The priority given to home care also implies a restructuring of the home care sector, based on a complex pricing system and offering precarious working conditions.

$\rightarrow$ Better coordination of the various mechanisms and actors, belonging to different policy sectors - health or social protection -, involving different territorial levels and a multiplicity of professionals, is another solution that has been proposed both at national and local level. Various mechanisms have been created, such as networks, pathways, coordination or integration mechanisms, to facilitate the continuity of care for the elderly and to rationalize the field of care for the elderly.

$\rightarrow$ Prevention is also a pillar of recent policy proposals.

Despite significant efforts, many problems remain:

- Level of the rest to be paid by the dependent person and his or her family

- Doubts about the quality of service delivery or the efficiency of spending

- Increased expenditure expected as the population ages

The law of 28 December 2015 on the adaptation of society to ageing only partially responds to these challenges, it improves APA in the home without, however.

${ }^{36}$ ESPN Thematic Report on Challenges in long-term care, France 2018 